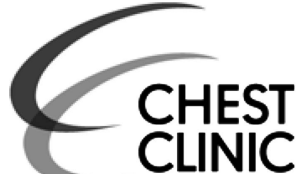

'Pulmonary Division, Cantonal Hospital of Muensterlingen, Muensterlingen, Switzerland ${ }^{2}$ Pathology Division, Cantonal Hospital of Muensterlingen, Muensterlingen, Switzerland

\section{Correspondence to}

Dr Yvonne Nussbaumer-

Ochsner, Pulmonary Division,

Cantonal Hospital of

Muensterlingen, Spitalcampus

1, Muensterlingen 8596

Switzerland; yvonne.

nussbaumer@hispeed.ch

Received 10 February 2015 Revised 23 February 2015 Accepted 26 February 2015 Published Online First 31 March 2015

\title{
Endobronchial lipoma mimicking bronchial carcinoid tumour
}

\author{
Yvonne Nussbaumer-Ochsner, ${ }^{1}$ Frank Rassouli, ${ }_{1}^{1}$ Frank Uhlmann, ${ }^{2}$ Robert Thurnheer ${ }^{1}$
}

A 68-year-old smoker on aspirin/clopidogrel due to recent percutaneous coronary intervention (PCI) / stenting presented with intermittent haemoptysis. Bronchoscopy revealed an endoluminal tumour in a right-lower-lobe segment (figure 1). No biopsy was taken due to bleeding risk. Aspirate analysis showed sparse cells with granular cytoplasm, and a presumptive diagnosis of bronchial carcinoid was made. CT scan showed no lymphadenopathy. After stopping clopidogrel and absent signs for progression on CT scan/bronchoscopy, right-lower lobectomy was performed. Histological analysis revealed a submucosal lipoma (figure 2).

Differential diagnosis of endobronchial tumours encompasses benign (eg hamartoma, lipoma) ${ }^{1}$ and malignant lesions (eg bronchial carcinoid, metastasis, mucoepidermoid or adenocystic carcinoma). ${ }^{2}$ Biopsy has to be weighed against bleeding risk especially if a bronchial carcinoid is considered. Retrospectively, a lipoma could have been suspected based on the density of the lesion $(-122 \mathrm{HU})$ and the endoscopic appearance. The management of our case was misled by the cells with granular

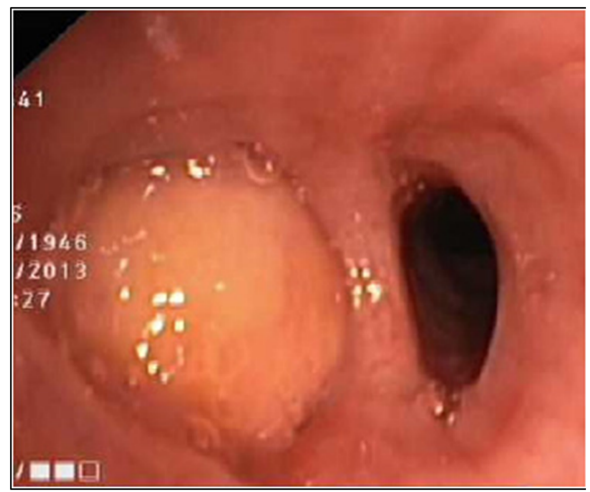

Figure 1 Bronchoscopic view of a well-circumscribed, yellowish polypoid mass obstructing a segment of the right lower lobe.

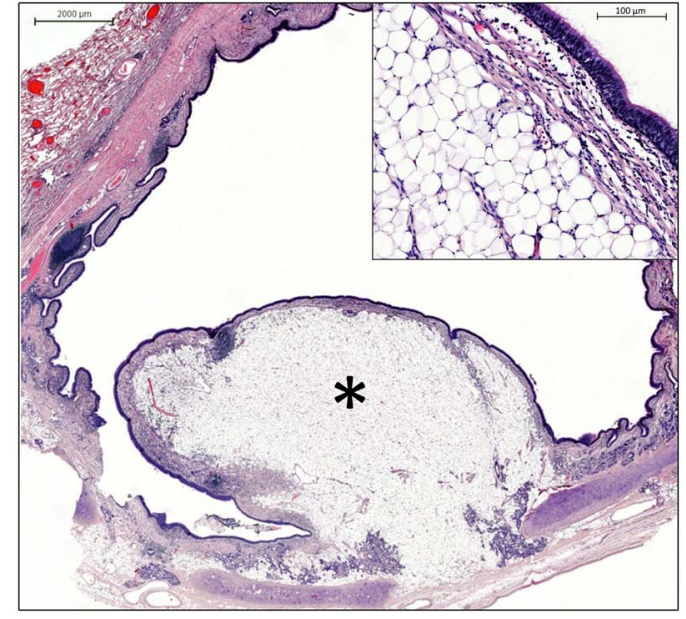

Figure 2 Sagittal section through the bronchus containing the endobronchial tumour (asterisk). The tumour originates from the submucosal layer of the bronchus. Upper edge: magnification of the tumour surface. The tumour is composed of mature fat and covered by respiratory epithelium.

cytoplasm in the aspirate-arising from a ganglion beside the lipoma-and underlies the importance of a multistep-based diagnostic algorithm.

Contributors $\mathrm{YN}-\mathrm{O}$ was responsible for data collection and writing the manuscript. FU was responsible for the acquisition of the figures. FR and RT revised the manuscript.

Competing interests None.

Patient consent Obtained.

Provenance and peer review Not commissioned; internally peer reviewed.

\section{REFERENCES}

1 Cao D, Sun Y, Yang S. Endobronchial lipoma: an unusual cause of bronchial obstruction. Case Rep Med 2011;2011:939808.

2 Li Z, Zarogoulidis P, Kougioumtzi I, et al. Surgical approaches of endobronchial neoplasms. J Thorac Dis 2013;5 (Suppl 4):S378-82. 